\title{
Det minoiske udbrud \\ - nu nøjagtigt dateret
}

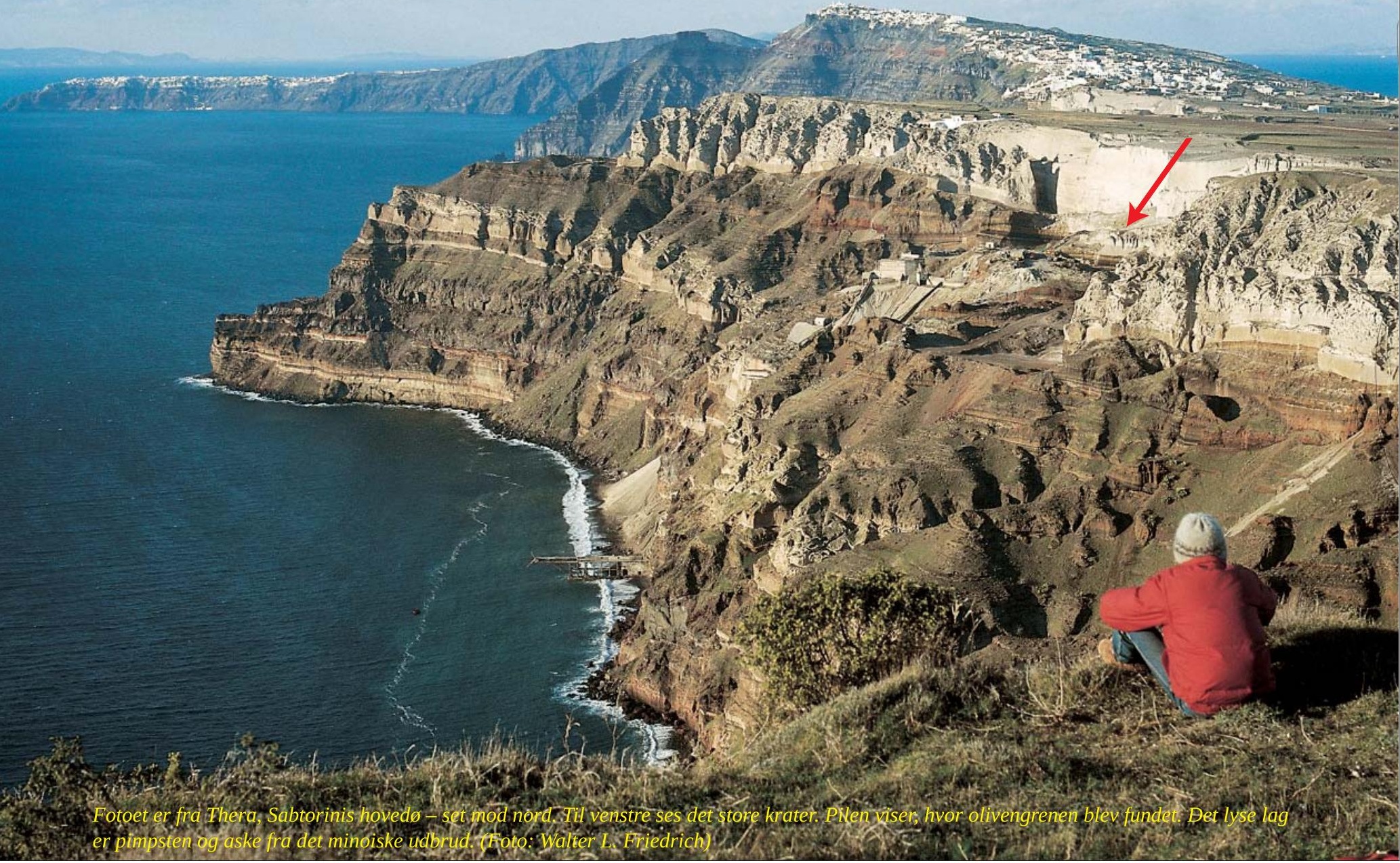

Af geolog Walter L. Friedrich, Geologisk Institut Aarhus Universitet og geolog Ulla V. Hjuler, GeologiskNyt

Diskussionen om dateringen af bronzealderens største vulkanudbrud ser nu ud til at være afsluttet. En gruppe naturvidenskabelige forskere fra Aarhus Universitet har nemlig dateret en olivengren til $1613 \pm 13$ f. Kr. Det er 100 år tidligere end førhen antaget.

Da den japanske kunstner Hokusai malede sit billede af kæmpebølgen, kunne han af gode grunde ikke vide, at en kollega fra bronzealderen forinden var blevet fascineret af samme motiv. Hokusai malede sit tsunami-billede omkring 1700, og den anonyme kunstner fra den græske ø Santorini skabte sin tsunami-fresko - formentlig verdens ældste gengivelse af en tsunami $-\mathrm{i}$ perioden $1613 \pm 13 \mathrm{f}$. Kr.
Forkullet fund

At man nu kan datere denne fresko og alle de andre fantastiske arkæologiske fund i samme tidshorisont fra Akrotiri-udgravningen, "Bronzealderens Pompeji", med så stor nøjagtighed (95,4\% sandsynlighed), skyldes det, at en geologistuderende bogstaveligt talt snublede over en forkullet gren, der lå på hans vej. Tom Pfeiffer fra Geologisk Institut i Århus, der med henblik på sin ph.d.-afhandling var i færd med at studere askelagene fra den såkaldte minoiske

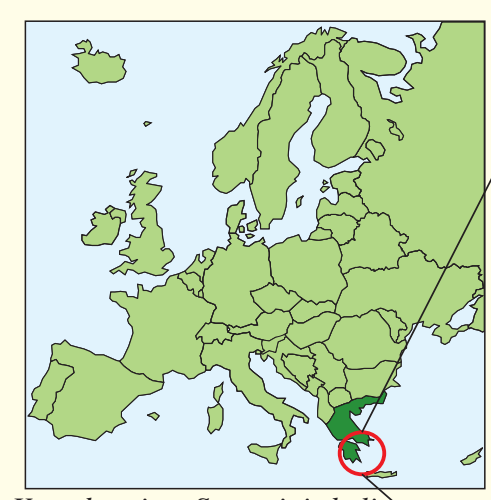

Kort der viser Santorinis beliggenhed. Hovedøen, Thera, har et areal på knap 75 km². Til sammenligning har Lcesø et areal på ca. $114 \mathrm{~km}^{2}$.(Grafik: UVH)

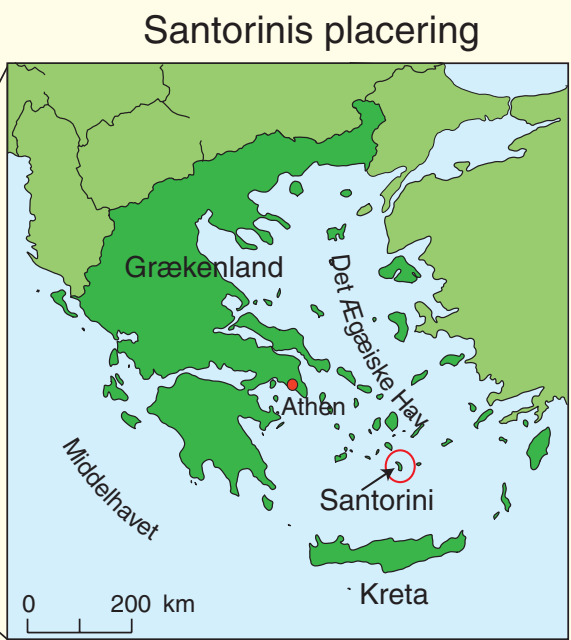

0 \section{$-$

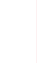


eruption på Santorini, et af verdens største vulkanudbrud, bemærkede straks, at der var flere grene højere oppe i den stejle næsten utilgængelige klippevæg.

Da hans vejleder, Walter L. Friedrich, besøgte stedet sammen med ham, havde Tom Pfeiffer for længst fundet ud af, at det drejede sig om et oliventræ, der var blevet levende begravet af de op til $60 \mathrm{~m}$ tykke pimpstensmasser, som vulkanen havde slynget ud. Der fandtes ud over grene også blade og rødder af træet. En gren havde dog mange årringe, og et stykke blev undersøgt på kulstof-14-laboratoriet ved Fysisk Institut i Århus. Det skal vi vende tilbage til om et øjeblik. Først lidt om nogle de tidligere dateringer, som har været brugt som grundlag for historieskrivningen.

\section{Arkæologiske dateringer}

Inden for arkæologien og geovidenskaberne anvendes såvel absolutte som relative dateringsmetoder. Ved de relative metoder sammenligner man sit fund med allerede daterede objekter for der igennem at forsøge at tidsfæste fundets alder - dette kræver et stort sammenligningsmateriale og detaljeret kendskab til arkæologien og geologien - både i lokalområdet og for arkæologiens vedkommende - $\mathrm{i}$ lande med kulturer, der har haft betydning for fx handelsudveksling.

Ved absolutte dateringsmetoder kan man mere præcist fastsætte alderen $\mathrm{i}$ år $\mathrm{fx}$ vha. radiometriske metoder eller termoluminescens.

I udgravninger fra det antikke Avaris i det østlige Nildelta er der fundet flere tusinde brudstykker af minoiske fresker, der er blevet sammenlignet med lignende fund på Kreta og Santorini, og som muliggør en korrelation med den ægyptiske kronologi, der baserer sig på Farao-dynastierne. Fundene spiller en vigtig rolle for diskussionen om tidsfæstelsen af det minoiske udbrud, der af nogle forskere dateres til ca. $1.550 \mathrm{f}$. Kr.

Også andre fund som fx keramik og seglaftryk har kunnet give et fingerpeg om forbindelser til Egypten - for få årtier siden gav denne sammenligning arkæologerne grund til at antage, at den minoiske eruption kunne have fundet sted omkring 1.500$1.550 \mathrm{f}$. Kr.

\section{Termoluminescens}

Tidligere har der også været foretaget dateringer på nogle potteskår fra Akrotiriudgravningen vha. termoluminescens-metoden. Disse målinger (Friedrich 1987) gav en alder på $3.600 \pm 200$ år., men da usikkerheden var for stor, spillede denne måling aldrig nogen rolle.

Termoluminescens-metoden er baseret på datering af mineraler. I naturligt forekommende mineralers krystalstruktur indfanges og ophobes der elektroner (elektronfælder) som følge af naturlig radioaktiv bestråling fra $\mathrm{fx}$ uran og thorium, der findes i det omgivne materiale og fra bl.a. kosmisk stråling.

Ved brænding af ler frigøres de ind-
Udsnit af fresko fra udgravningen ved Akrotiri, der viser en tsunami og tre lig samt vragrester og et skib. Billedet blev ikke fcerdigmalet; arkcologerne fandt maleredskaber og mørtel i samme rum - det tyder på, at kunstneren måtte forlade stedet $i$ al hast (Foto: Fra bogen "The Wallpaintings from Thera" af Christos Doumas)

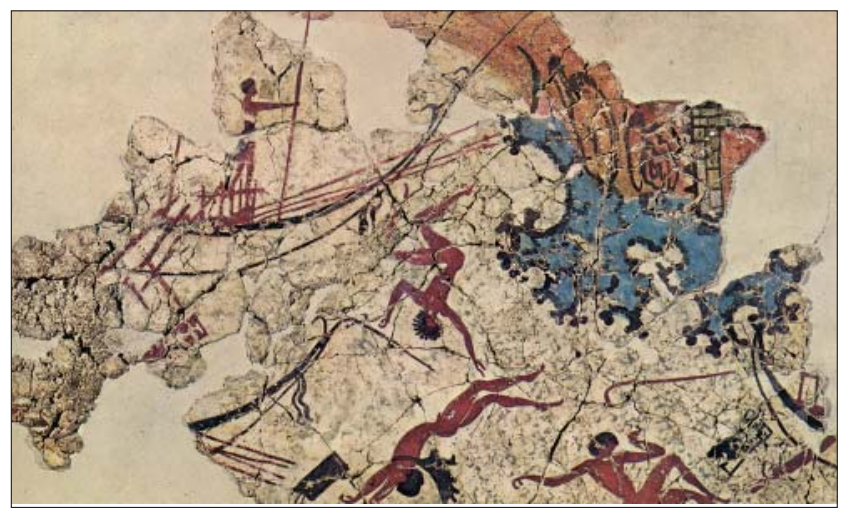

fangne elektroner i materialet, og man siger, at det "nulstilles". Mineralerne i potteskår, fælder.

Det er specielt kvarts- og feldspatkorn, der egner sig til dateringen (da disse mineraler er "stabile"). Jo længere tid, potteskåret har ligget længe i jorden, desto større er mængden af indfangne elektroner. Man antager normalt, at doseringsraten er konstant, og det betyder, at antallet indfangne elektroner er ligefrem proportionalt med den tid, der er gået, siden potteskåret blev "nulstillet". Hvis potteskåret nu varmes op til omkring $500{ }^{\circ} \mathrm{C}$, slipper elektronerne ud af fælderne, hvorved der udsendes energi i form af lys - luminescens! Hvis man måler høje mængder lys, har der været oplagret mange elektroner i fælderne, hvilket igen betyder, at den oprindelige strålingsdosis har været kraftig.

\section{Kulstof-14-datering}

Kulstof-14-metoden er en radiometrisk dateringsmetode af kulstof i organisk materiale, der bygger på dannelsen af radioaktivt kulstof $\left(\mathrm{C}^{14}\right)$, der udgør en lille del af alt der ligger i jorden, danner nu nye elektron- kulstof. Kulstof-14 indeholder to neutroner mere end ikke-radioaktivt kulstof $\left(\mathrm{C}^{12}\right) . \mathrm{C}^{14}$ dannes, når kosmisk stråling rammer atmosfæren - her går neutronerne i forbindelse med kvælstof-14, hvorved der dannes kulstof-14 og protoner.

Både $\mathrm{C}^{12}$ og $\mathrm{C}^{14}$ optages i plantevævet, der spises af dyr og mennesker, mens de lever. Når organismen dør, ophører kulstofoptagelsen, og indholdet af $\mathrm{C}^{14}$ aftager herefter pga. henfaldet til kvælstofisotopen $\mathrm{N}^{14}$, der er stabil. Halveringstiden er på 5.730 år, og sætter man mængden af $\mathrm{C}^{14} \mathrm{i}$ den døde organisme i forhold til den oprindelige mængde, får man nu alderen på organismen.

Metoden er noget usikker, idet mængden af kosmisk stråling og dermed mængden af C14 kan svinge en hel del fra år til år.

I 1986 blev der målt på en del frø fra Akrotiri-udgravningen, der gav en alder på ca. 1645 f.Kr.

\section{Iskernedatering}

Endelig skal iskerneboringerne fra Grønland nævnes. Den længste boring nåede ned på godt $3 \mathrm{~km}$, og det anslås, at alderen ved bunden af indlandsisen er ca. 200.000 år.

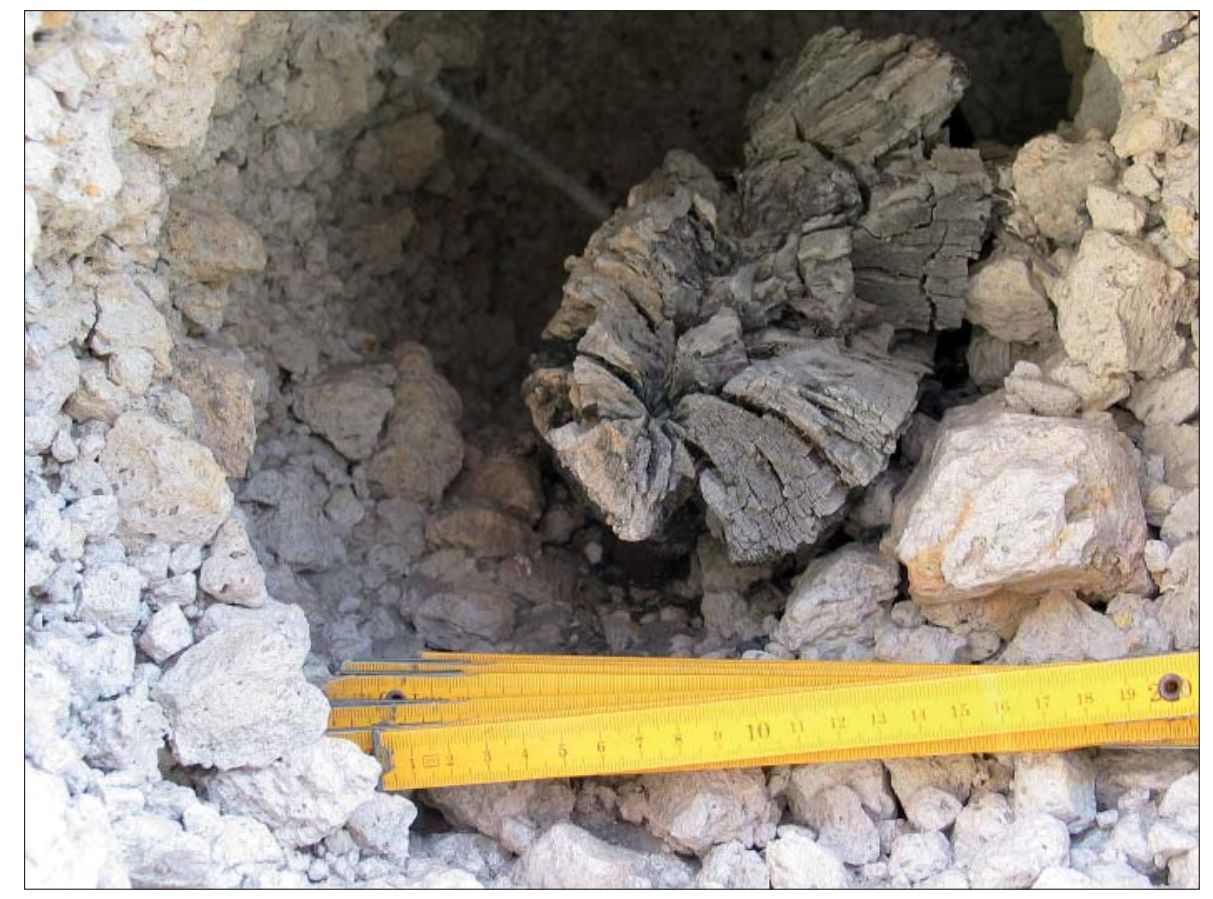

Olivengrenen som den blev fundet i pimpstenen. (Foto: Walter L. Friedrich) 


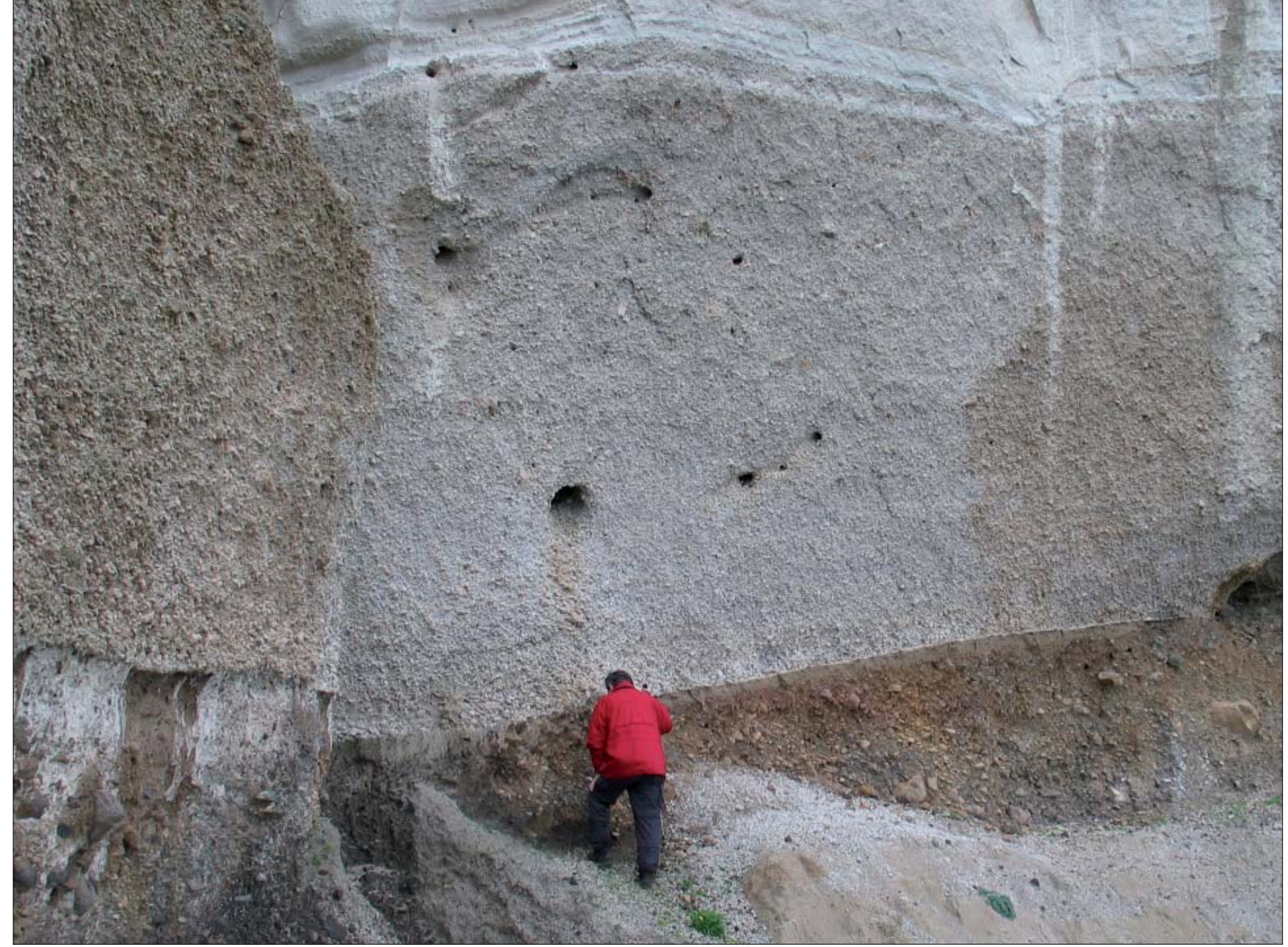

Walter L. Friedrich lige under hullet i pimpstenen, hvor grenen blev fundet. På væeggen ses omkring 7 huller, som hidrører fra oliventrceets grene Det nederste brune lag er den oprindelige jordoverflade, hvori oliventrcets rødder har siddet. (Foto: Tom Pfeiffer)

Hvert år har sat sit præg i isen, og ved fx et kraftigt vulkanudbrud vil isen være beriget med svovlsyre, idet svovlsyreholdige gasser fra meget voldsomme vulkanudbrud når op i stratosfæren og går i forbindelse med vand, og siden føres mod polerne. Også askepartikler kan indlejres $i$ isen. En sammenligning af analyser fra disse boringer har givet en alder på det minoiske udbrud på $1642 \pm 5$ år (Vinther et al. 2006).

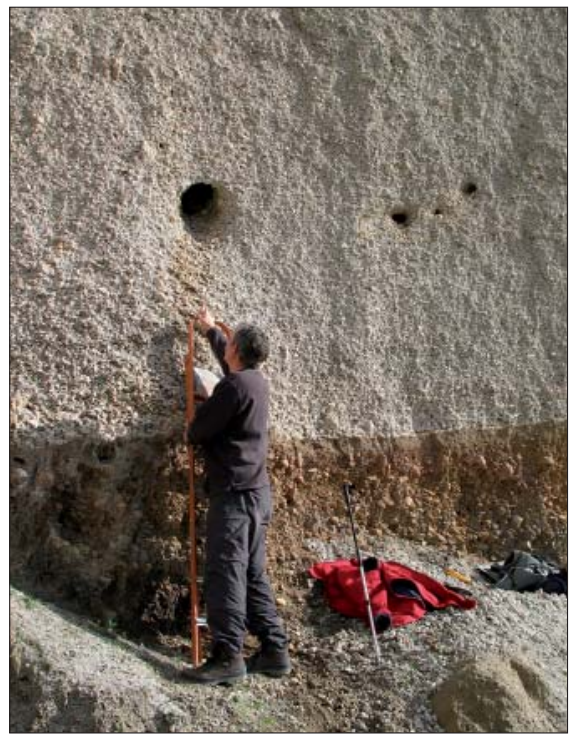

Der mangler lige en halv meter op til hullet.... (Foto: Tom Pfeiffer)

\section{Olivengrenen}

Undersøgelsen af den føromtalte olivengren viste, at man havde med et helt enestående fund at gøre, da alderen - som Jan Heinemeier fandt frem til - lå netop, hvor man forventede, at alderen for det minoiske udbrud skulle ligge.

Det blev dog besluttet, at den fortsatte undersøgelse skulle foretages i Heidelberger Akademie der Wissenschaften, hvor Bernd Kromer og hans team kort forinden havde målt det stykke af kulstof-14-kalibreringskurven, som var relevant for undersøgelsen. Michael Friedrich fra Hohenheim/Heidelberg undersøgte derefter en prøve af træet ved hjælp af røntgentomografi, hvorved 72 årringe kunne tælles, hvilket uden dette trick ikke ville have været muligt. Da grenene havde barken bevaret - et tegn på, at det le- vede, da det blev overdænget af pimpstensregn af vulkanen i stående position - kunne dateringen af den sidste årring give den nøjagtige alder på den enorme eruption.

Forskerteamet fra Århus og Heidelberg har nu offentliggjort en artikel i det renommerede tidsskrift Science (Santorini Eruption Radiocarbon Dated to 1627-1600 B.C. publiceret 28. april 2006), hvori de fortæller, hvordan de med en speciel statistisk teknik kaldet "wiggle-matching" har kunnet udnytte den sidste årring, som angiver udbrudstidspunktet.

Dateringen er den mest direkte og præcise tidsbestemmelse af eruptionen. Colin Renfrew, University of Cambridge udtaler til Science, at dateringen nu på overbevisende måde løser dateringsproblemet med Santorini-udbruddet.
Et tvcersnt af olivengrenen med angivelse af årringene. Den yderste årring ligger leengst til højre og blev dannet samtidig med vulkanudbruddet, der forkullede trceet. (Røntgentomografi fra artiklen $i$ Science)

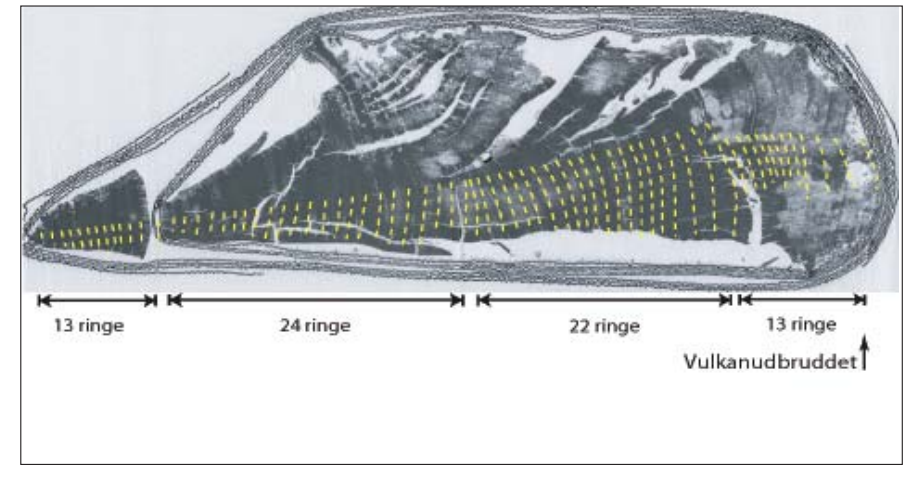




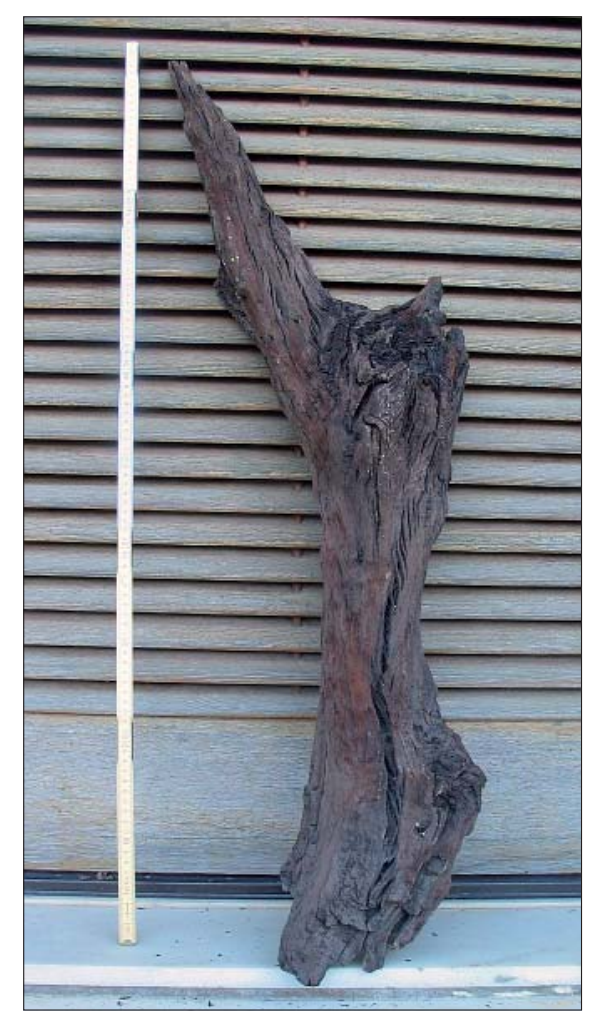

Den én meter lange gren, i hvilken den sidste årring er bevaret. (Foto: Walter L. Friedrich)

Ligesom Hokusais billede, hvor der antydes en sammenhæng mellem bølgen og vulkanen i baggrunden, er Santorini-freskoen linket til et vulkanlandskab. Og det geologiske udsagn er det samme i begge billeder: Tsunamier, jordskælv og vulkaner findes i jordens seismisk aktive øbuer, som Sumatra-tsunamien 2005 viste med al tydelighed. Kort efter, at bronzealder-kunstneren havde lagt sidste hånd på sit tsunami-billede, som

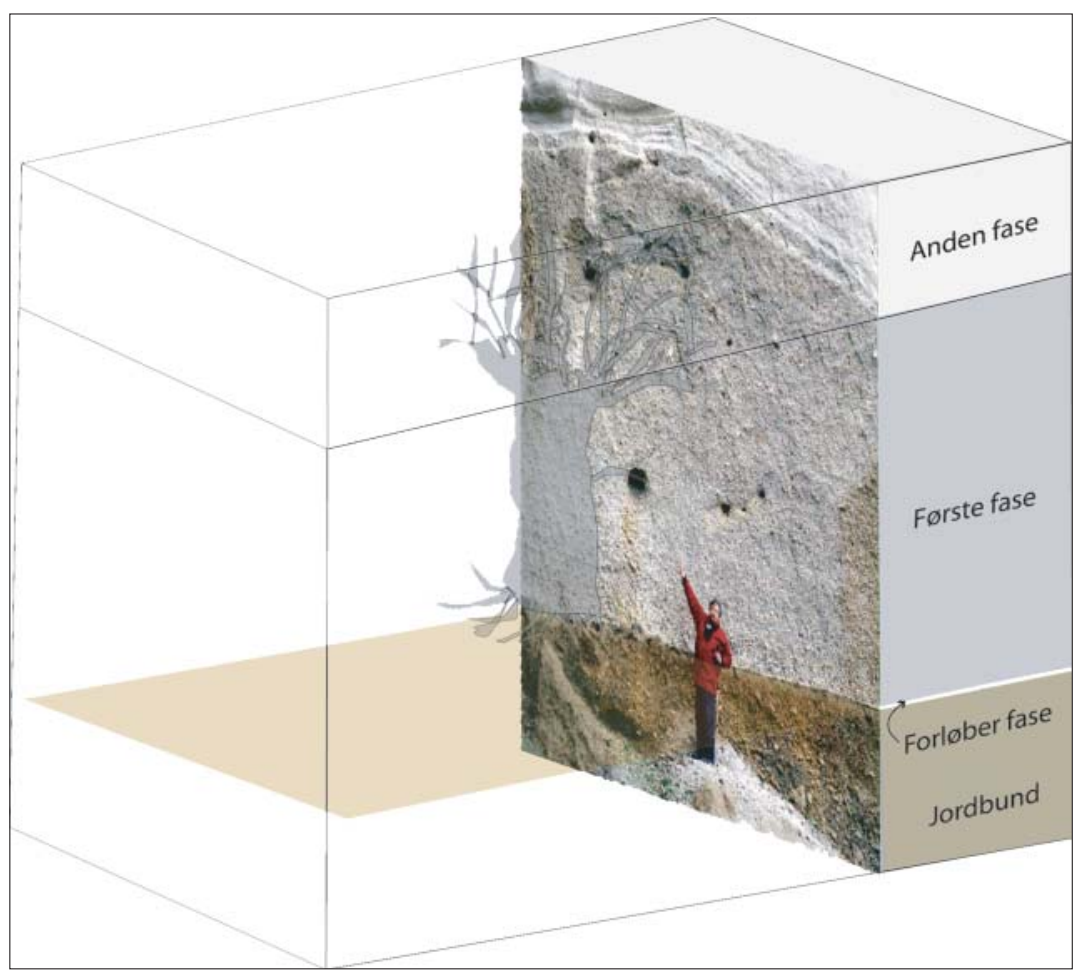

Tegningen viser skematisk, hvor oliventrceet har stået, inden det styrtede i havet 150 meter liengere nede. Walter L. Friedrich peger op mod hulrummet, hvori grenen blev fundet. (Foto: Tom Pfeiffer/grafik: Walter L. Friedrich)

med al tydelighed var et tegn for seismisk uro i undergrunden, fandt Bronzealderens største vulkankatastrofe på Santorini sted med globale klimaforandringer til følge.

Den lagde op til $60 \mathrm{~m}$ pimpsten over det blomstrende bronzealdersamfund, spredte enorme mængder af aske over den østlige del af Middelhavet og satte dets spor så langt væk som til den grønlandske indlandsis.
Således kunne man med en forkullet gren ikke kun datere verdens ældste tsunamibillede, men også bronzealderens største vulkankatastrofe. Alle de pragtfulde fresker fra Santorini er gengivet i Christos G. Doumas bog; "The Wallpaintings from Thera".

En udførlig beskrivelse af Santorinis naturhistorie udkommer snart i bogform på dansk (Ilden I Havet) hos Århus Universitetsforlag.

\section{Wiggle-matching}

Af lektor Jan Heinemeier, Institut for Fysik og Astronomi, AAU og geolog Carsten Kjaer, Aktuel Naturvidenskab, AAUO)

Når planter gror, optager de $\mathrm{CO}_{2}$, som indbygges i det organiske materiale. En vis del af atmosfærens $\mathrm{CO}_{2}$ indeholder den radioaktive udgave af kulstof - kulstof-14. Atmosfærens indhold af kulstof-14 svinger op og ned over tid, og når et træ vokser, vil det således "optage" disse svingninger i dets forskellige vækstlag (årringe). På baggrund af analyser af kulstof-14-indholdet i sekvenser af årringe i træer med kendt alder, har man med stor præcision kunnet rekonstruere en universel kalibreringskurve over sammenhængen mellem de målte kulstof-14 aldre og de kendte kalenderaldre, foreløbigt godt 12.500 år tilbage i tiden. De observerede svingninger ("wiggles") i kurven afspejler svingningerne i atmosfærens indhold af kulstof-14.

Kalibreringskurven bruges af forskerne som reference, når de daterer vha. kulstof-14. For at få en nøjagtig alder kræver det, at man er sikker på, at det organiske materiale faktisk har været levende helt ind til det tidspunkt, man er interesseret $i$ at datere (træ brugt som byggemateriale kan $\mathrm{fx}$ være meget ældre end huset), og så kræver det, at man kan lave en række C-14 målinger af materialet, som man ved har en bestemt tidsmæssig rækkefølge. Er disse krav opfyldt kan sekvensen af målinger kalibreres mod referencekurven og dermed give en præcis datering af materialet. Dette kaldes "wiggle-matching", og det er denne teknik, forskerne har brugt til at datere olivengrenen fra Santorini. Normalt giver en pæn, glat sektion af kalibreringskurven den mest præcise kalibrerede alder i kalenderår,

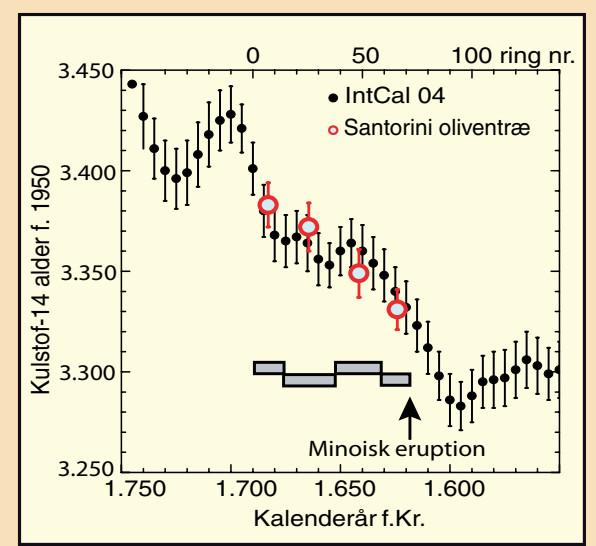

men har man en hel tidsfølge som her, giver en kraftig struktur med wiggles i kurven de mest nøjagtige resultater, fordi dateringerne kun kan falde på plads som i et puslespil på ét bestemt sted på kurven, så kalenderalderen bliver helt entydigt bestemt. 